\title{
MODERNISM AND POSTMODERNISM IN ARCHITECTURE, AN EMPHASIS ON THE CHARACTERISTICS, SIMILARITIES AND DIFFERENCES
}

\author{
Niki Amiri \\ MA, Department of Architecture, Islamic Azad University of Babol, Iran
}

\begin{abstract}
This research is conducted in order to describe the modernism and postmodernism in architecture, as well as the characteristics, similarities and differences between these two with each other. The research methodology is in library form and by using of books, domestic and foreign articles and related websites in this research. Among the features of each of styles can name the efficiency and pragmatism in modern architecture and adherence to a kind of unusual metaphysics in post-modern architecture. About the similarities and differences between these two styles can be said that these two styles do not have a lot of similarities but post-modern architecture has followed some aspects of modern architecture and has been created the similarity between them. Both architectural styles have been effective on socio-economic and environmental conditions and in particular philosophical conditions .Modern architecture had been involved with a big problem with the name of war and inevitably has wanted to fix it but post-modern architecture has came to action with a sense of shortages of this style and at the same time freely and rich intellectual backing. Modern architecture began with the civil period that attention to industry had been a principle and to succeed in the industry should be sacrificed anything. Ranging from human to conditions and human life .Postmodern era has been formed in contrast point with giving value to human and his/her emotions.
\end{abstract}

Keywords: modern architecture, postmodern architecture, features, similarities and differences

\section{INTRODUCTION}

Architecture determines the facts or superior values as an art work. Architecture gives visual expression of ideas. Ideas make meaningful something for human, because they organize the reality. Architecture as an original art represents the culture and civilization of a nation and race. So we need somehow to review their architecture for a full understanding of humanity and his/her opinions, whether in the past or present. There is no doubt in the importance of architecture and its benefits and its efficiency. But with the arrival of modern architecture, special change was created in the architecture and created changes in other arts and even in human thinking. With the arrival of this style of architecture can no longer outline a special feature for different architectures and somehow brought uniformity. In this discussion it is trying to show that what features do the post-modern and modern architecture have and their similarities and differences appear by examining each of them.

But the questions arise here such as whether modern or post-modern architecture were created at once? Are these undisputed subordinate of need of their own times? Was modern architecture and creating it useful or not? Is post-modern architecture a reaction against modern architecture?

Can postmodern architecture to meet deficiencies and shortcomings of modern architecture? In order to answer to questions such these, first were investigated two architectural styles and then the way of formation and features of each one to get the similarities and differences of these two architectural styles. 
The term of postmodern was used for the first time since 1976 in the art world and in general, covers a willing that has created in front of absorption modernism. The basis of modern architecture that was the universal and dominant style in the twentieth century is rooted in the changes of Renaissance era that its origin had been the city of Florence in northern Italy about 400 years before the advent of modern architecture.

The modern world offers a different vision of the universe versus old world that arose from the intellectual and human-oriented beliefs (Ghobadian, 2003). Modern architecture was formed as an architecture school with a comprehensive theoretical foundation and constructed buildings according to modern thought of the late 19th century. This architecture was known in Chicago City of America and in Europe in cities like Paris, Berlin and Vienna (Ghobadian, 2003).

Post-modern architecture was raised as an important subject and style of the sixties and infrastructural criticisms were entered to the thought of logicism and technology-oriented of modern architecture. Robert Venturi called into question the modern philosophical principles and refused the technologyoriented insight and wanted to pay attention to human characteristics instead of that.

Venturi replied to the motto of less more of Mies Vander Rohe in less boring way. In his view, architecture is not only a technique and technology but also there is a complex issue in the building that cannot be ignored. He rejected international style and in its place believed in the contextualism because every building is designed based on cultural, social, historical and functional fields and its special conditions (Ghobadian, 2003).

\section{MODERN AND POST-MODERN MODERN ART}

The foundation of modern art is based on shape and form. Modern art is accompanied with a kind of formalism and anti familiarity and alienation. Modern society thrown away traditional and mythological elements from the domain of knowledge by relying on human reason and intellectual logic and objective facts and social recognitions and subjective qualities entered in to the art field both in terms of separation and sense of aesthetics (Kanti) (Raygani, 2014).

Artistic modernism characteristics are: identity and unity, independence and self stability.

Unity means establishing a link between discontinuous elements and integration in the multiplicity and confusion. Independence and self stability mean being far away of any external ornament and being internal its nature .Another feature of modern art is emphasis on the unconscious strains and mentality (Surrealism). Modern art distinguishes between authentic art and mass art (Frankfurt School). Modern art is simple and universal, and is far away of local standards (modern architecture and International Style). Modern art is abandoned from the determinations and social responsibility (formalism). And finally, modern art is of concept, is not a representation of reality and thus is not also indicator (Alizadeh, 2012).

\section{POST-MODERN ART}

Postmodern art is not unlike the modern and unitary art but also is pluralism, self-conscious, eclectic, and mixed and contextualize. Post-modern art does not discriminate between fine art of mass art. So this time mix them deliberately causes to create the kind of satire and humor. Post-modern leads to create eclecticism and humor with the combination of past and present styles in architecture with a combination of classic style, detective, western, etc in literature. Using a combination of "multimedia" to create an art work is one of the approaches of postmodern .Postmodern knows important socio and historical context In contrast to modern. In the post-modern art temporality and historical existence of human is the focal issue of effect. Modern artist tried to organize the disorganization and without shape world within the framework of its effectiveness and considered mentality and intellectual work prior to anything, but postmodern artist knows the effect more important and more valuable than his/her Intention and desire. In his view, organize is futile work. He /she want to make close him/her 
to the overall context of culture and society. Postmodern periods are the transition period and leaving behind the aesthetics (Robert, 2009).

\section{MODERN ARCHITECTURE}

Modern architecture was as a milestone in the history of Western architecture or in other words in the history of world architecture, because for the first time, the attitude of the tradition, history and past changed its direction as a source of inspiration of architecture and future and development were introduced as main objective and subject of architecture. Architects and theorists tried to make homogeneous the architecture as a science and technology with evolving world (Ghobadian, 2003). Modern architecture emerged in the form of global style, the style that took root after World War I and spread in the reconstruction of Europe after the Second World War. This style had its claim to reform architectural process and building design with abandon the no planning and traditional management through the adoption of a global system of architecture. This new architecture was organized with the norms of rational, and used of one of the most efficient materials such as concrete, steel and glass (Malpas, 2007).

Modern architecture is new and universal and rooted in concepts of construction that is appropriate to a modern industrial society, so that transformation and its composition, aim at the community that it is under the testing. Space was used with similar physical properties in it. Uses abstract form and tends to pure architecture (Jawdet, 2005). Modern architecture measuring usually pays attention to the concept of functionalism, so before anything pays attention to the effectiveness and efficiency. Some even believe that modernism was a slave of the power of capitalist rule and has sacrificed the architecture which means that the forms can be found of needs and few resources in logical way (Norouzi Borazjani, 2003).

Goal of modern architecture was "less is more" of the words of Mies Van der Rohe in the first stage and also Brankochy says, "The purpose of art is not simplicity but the person reaches to simplicity in the approach to the true meaning of things, against his/her ". This kind of simple is real in this type of new settlement. But the goal here was not limited to simplicity. Gidben has defined the second stage of development of modern architecture "urban humanize "and the third stage as the manifestation "new memorial orientation " that means to create buildings that makes symbolic the social, religious and common life of humans. He added "new regionalism" as a fourth point in 1954 and stated that the architecture before building any plans inevitably checks the way of life in place (Norouzi Borazjani, 2003).

Modern architecture is divided into three periods: the early, high and late that in its early modern is divided in to three Chicago, art movement and the movement of Futurism styles. supreme modern architecture, or the top of modern architecture was formed between the two World Wars I and II, means mainly in the twenties and thirties AD in Europe and in the early modern period still historicist styles such as Neo classical, romantic and especially eclectic had important as the popular and common styles in the west. One of the key and very important issues was the issue of industry, industrious production and technology in the excellence modern era (Ghobadian, 2003). Locorbusieh considered the use of steel girders and concrete and pre-fabricated, as the path of the future architecture and knows the pre-fabricating and high-rise making as only solution of future cities. Later modern architecture can be considered after World War II to the early 70's (Ghobadian, 2003).

Happened developments in the field of architecture in the last three decades of the last century caused to destabilize the pillars of only inclusive and universal style a major part of the twentieth century means modern architecture. These changes have rooted in fundamental intellectual and social changes and transformation of attitudes towards themselves and the world around in the West (Ghobadian, 2003). 
But, according to Jencks towns that their fundamental principles had been based on rationalism and engineering of work environment are considered as the culmination of modernism in architecture field (Malpas, 2007).

Modern functionalism theory believes that architecture merely acts to determine and meet the needs of the employer with a scientific analysis and modernism has had a contentious relationship with usage and nature that both are the body like structures., Locorbusieh almost is the only one among the modernisms who was in search of a proportional human-centric and modular system (Kit of relativism, 2007).

Michael Graves says the modern movement undermined the poetic form to win the non-figurative and abstract geometries by rejecting the human or humanism of the previous architecture. Modern architecture offers the solutions for the problems that must be solved that were pure and lean but are annoying and boring by conscious limiting the issues. As a result modern architecture is not at the same level with modern science of poetry or art that all have found the complexity and contradictions. Modern architecture accepted machine analogy rather than organic analogy. Machine is often designed based on natural systems, but application of formal pattern, prevented the architecture of direct reference to the nature (Kit of relativism, 2007).

\section{POST-MODERN ARCHITECTURE}

It can be said that postmodernism is an attempt to treat the problems and difficulties of modernism, and despite of promoting a kind of anomalies is considered a continuation of modernism and not as a reaction against it "(Jabiri Moghaddam, 2005).

Post-modern architecture seeks the identity of human and history of each nation and race is considered as part of the nation's identity. So they show cultural and physical history and as well as grammar of architecture of each ethnic in their architecture in each area.

But this show is not for duplication of the above cases, but what is related to the identity of a nation is updated in their buildings and appears based on the circumstances of time and place in new and updated way. Therefore post-modern architects have no hesitation in changing proportions, colors and functions of historical signs.

Post-modern image of the city has been designed as the place of images that is in competition with other cities. Urban design paradigms based on the theories of post-modern architecture have criticized the development the lack of their economic and social aspects (Dibaj, 2011).

According to Marshall Berman, postmodernism is a complex and intertwined configuration of diversity of ideas, opinions that emerged in the late 1960s and still is active and in dynamic and expanding form in the late 1990s. The term of postmodern has followed many and various discourses. The process that still is continued (Rasouli, 2015).

Louis Kan, Robert Venturi, Michael Graves, Aldo Russi, Frank Grave, Charles Moore, James string and Ricardo Bafil consider as the most prominent faces among designers and architects of postmodern, although all of them are not happy and satisfied with this tag "(Nozari, 2000).

Other group of post-modern architects and urban designers (neoclassical) supported back to the bio force and beauty of pre-industrial forms. Ingersol criticizes this kind of historicism: Pre-industrial forms and spaces are not necessarily suitable for the post-industrial ways of life (Wiley Bie Oughlo, 1999).

Urban design in post-modern urbanism reflects a wide range of approaches of design, texts and applications. But common problems in design especially noted to revitalization projects in downtown, 
historic preservation and projects of increasing the public space (for example street design, reduce traffic and ... (Wiley Bie Oughlo, 1999).

In this way, this way of patching, merging and combination cannot consider as innovative or revolutionary initiative and radical in the post-modern, but also in fact is that thing that Harold Rosenberg called it " tradition related to new" (Mahlabani, 2013).

Many architectural historians do not believe that postmodernism can be considered as a style in accordance with the Baroque, modern, classic or gothic, it seems that postmodernism is a result of the crisis in concept of style and nothing more. As the last true style was born in the architectural history was modernism that was associated with indulge in functionalism and structural rationalization and brought architecture in to a crisis that postmodernism tried only to its speedy recovery. Effort of architecture to transform the memory and perhaps the removal it and the conversion of pre-modern human to modern human by using the architecture was the thing that stimulated the reactions opposite it more than all (Jawdet, 2005).

Post-modern building is a building that raises itself in front of modern architecture at the same time at two levels: one for architects and limited group of enthusiasts that pay attention to certain concepts of architecture and another for public by local residents, who pay attention to other aspects such as comfort, tradition and way of life. In this way post-modern architecture seems to be a hybrid and cross. It can be similar to the effect of a classical Greek temple (Jawdet, 2005).

Robert Stern, Robert Venturi and Charles Moore have been considered as the founders of postmodern historicism that theoretically have changed the focus and emphasis from the independent formalism and modern to search for meaning. Stern counts three main areas of attention of these postmodern architects that all are related to the production of meaning: the facade, the city and the idea of "cultural memory." He calls these three areas of activity or the principle that emphasize on the attentions as decorationism, contextualism and gesturism. According to Stern, in the forms of postmodern historicism movement is hidden a kind of realism because these forms are identities $\mathrm{f}$ "social, cultural and political environments that have created them'. All three principles of stern consider an important role to date in the production and creation of meaning in postmodern architecture (Kit of relativism, 2007).

Post-modern architecture pays attention to dealing of critics with large-scales and available styles, the adoption of regional identity and return to the practical traditions. Post-modern architecture in the light of process that Jencks calls it "double coding" is a process that is acceptable also for special and general and popular people and is suitable for the designer and the consumer, by borrowing the styles of different periods and assistance of other monuments in its designs is diverse-oriented and eclectic (Ameri, 2012).

Replacement imitations of post-modern are not of earlier styles means a return to pre-modern period. Post-modern uses of pre-modern components in a way that recognizes also the styles that contemporary style is originated from it and integrates them in its ultra-modern designs in trustful way. Post-modern architecture tries to give human aspect to social environment Instead of changing the identity of the inhabitants of social environments in order to adapt them with preset rational layouts and at the same time have the maximum use of materials and ingredients and obtained progresses in modern fields in the field of construction techniques. (Malpas, 2007).

\section{FEATURES OF MODERN ARCHITECTURE}

Modern architecture focuses first and foremost on the efficiency and pragmatism, and uses the style and tools that has not had a history of such use to this size and in a way tries to develop in the modern era and uses all possibilities to achieve this purpose (Kit of relativism, 2007). This use causes to restrict the human role in its creating and whether causes to superior the technology on human. This 
goal is possible better that is with the lowest cost and highest performance and the best way is that we resort to technology and scientific estimates. Modern architecture at the same time, has a holistic mode, means due to the fact that buildings are built in industrial way finds breadth and comprehensiveness and is not for the unique of a person or a particular style.

This architectural style, acts to meet the needs and because it uses a single form is the anti-decorated, anti-show, anti metaphor, anti-historical, anti remembering and anti-humor and the meaning has been lost in this architectural style in a way (Kit of relativism, 2007).

Means architecture does not transmit the specific meaning and concepts and does not seek to answer to question or reaction to a particular point of view. Christian Harris, philosopher and lecturer at Yale University believes that the feature of "objectivity" of modernity has improper benefits. First, the physical environment has been changed to the materials in the hands of human so that exploit of it in blind and unaccounted way and second, detailed architecture is from technological culture that demands "machines for living" not demand the machines (Kit of relativism, 2007).

From the perspective of Zavari modern architecture has characteristics including: 1 design based on open plan 2- creates the absolute relationship between internal and external space, flexibility and freedom to create interior walls 3. Collect all the positive points, spatial experiences throughout history in modern architecture 4 . The use of the new technology specially glass instead of tall walls. But Locorbusieh also knows other quintuple principles such as high making, garden on the roof, the application of pulled window of open facade and the ceiling of the console as principles of modern architecture (Alizadeh, 2012).

\section{FEATURE OF POST-MODERN ARCHITECTURE}

Post modern architecture due to the weaknesses in modern architecture, tries to solve them and create an atmosphere that is different and better than the modern period. Postmodernism is non-exclusive in general against modernism .Means postmodern are finding ration for modernity in the twentieth century. One of the characteristics that postmodernists consider for themselves is to follow their form unusual metaphysics (Jawdet, 2005). Postmodernists say though Metaphysis inks and religious principles are destroyed, but there is still a general principle and it is that performance will remain spiritual. Their spiritual realm states like surrealist painters around virtual or explicit metaphors in a form of architecture (Jawdet, 2005).

Among the characteristics of post-modern architecture can be noted the following points:

- Social, cultural, historical and economic characteristics of people who use these buildings.

- Urban characteristics and the features of streets, alleys, shop

- $\quad$ climatic conditions and humidity, heat and cold conditions

- $\quad$ The way of daily living of people who live in building, their needs, their habits, how to use and their mental backgrounds and relationship with biological forms.

The post-modern architecture is also called pop or folk architecture because are used of the popular and interesting decorations and colors for the people in this architecture. Unlike modern that special people can understand its abstract concepts and meaning. Post-modern building has a duality in rules and concepts, one for the intelligentsia people and the other one for the general public (Ghobadian, 2003).

Of other features of post-modern architecture is that artists of postmodern have provided human shape and other recognizable forms again in their works and finished long-term domination of abstraction that was started with Cubism, Constructivism and Suprematism. In the post-modern architecture, using historical styles or recognizable components of specific styles has similar meaning and purpose. According to Jencks post-modern architecture has features including: 
- It is a kind of pluralistic architecture-a highly eclectic that adopts of difference and distinction and otherness of the praising and different styles and languages.

- This eclecticism causes in a diverse kind a kind of harmonization and dissonant harmony, a kind of use of antithesis materials and a kind of paradox that is the second post-modern features. This mutual aversion is humorous and satirical

- $\quad$ A kind of urbanism and urban living that buildings do not

- Seem alone and are a mixture of rituals, imitations and ridicules and causes to expand other buildings around themselves.

- $\quad$ Postmodern buildings have human character or human shaped.

- $\quad$ Reflects the relationship between past and present.

- $\quad$ Have eagerness to the meaning and content.

- $\quad$ Existence an additional encryption of composition and put together the styles.The building of postmodern does not reflect this or that but also reflects both this and that.

- Building of post-modern is multi-aspects or multi-valence. Means it can be a meaning of lot of things. Unlike being single-meaning or single-aspect the Modernist building. Post-modern architecture is multi-valence, non-exclusive, elusive, resonant and symbolic.

- $\quad$ They reinterpret the tradition means they are not a copy of mere past.

- Many postmodern buildings are longing to return to the center of the goal.

Post-modern architecture is a reaction against that thing that contemporary Austrian painter with the name of Frtis Handrtasr has called it tyranny of straight lines. An emphasis is on curved lines, emphasis on the unpredictable affairs, the emphasis on decoration and imitation and non-functional and beauty and in the new architecture. Transparent and mirror like surfaces and the winding millenniums are considered major elements in postmodern architecture (Nozari, 1999).

\section{SIMILARITIES AND DIFFERENCES IN MODERN AND POSTMODERN ARCHITECTURE:}

These two styles have not a lot of similarities, but post-modern architecture has followed in some aspects of modern architecture and has been caused to create the similarities between them.

For example, in regard to technology and use of most updated construction equipment and tools to facilitate work; another case is attention to improvement although this aspect is not clearly included in the postmodern but undeniably is seen in this style. Modern architecture and also post-modern architecture have a common story in use of technology and industry and in shaping to the identity of building. But the architecture does not seek the purity and simplicity in this context as modern architecture was looking for it (Bast and Kellner, 1997)

Another aspect of similarity is in a way paying attention to the need although in a performanceoriented modern architecture, is the main objective to answer to the requests, but in the postmodern also is involved this attention to the need of society and person means the same slogan of the post moderns that says: architecture should not be done by one person but also many people should be involved. At the same time is in the center of the customer's attention and taste. This means attention to the needs and a kind of request of human beings as we see in the postmodern in a way. Another similarity that can be regarded between these two styles is a positive aspect that has reached of modern architecture to the post-modern architecture and it is relying on management and planning that separates the modern period of traditional period that can be observed in this period. In terms of similarity between these two styles can be applied this interpretation that the post-modern architecture has put "feet on the shoulder of modern " that it means paying attention to modern architectures and its evolution in order to respond to more new needs. Disagreement and differences of these two architectural styles seem to be more than their similarities. Modern architecture in the original sense of word is passing the history and the past while in postmodern the strict attention to the tradition and history of each culture and civilization is one of the main aspects of this architecture style. 
In other words, Bast and Kellner believe that "modern architecture denies history while post-modern architecture digs it out because of its rich stylistic and symbolic resources" (Bast and Kellner, 1997).

Modern architecture with the goal of globalization (i.e. international style) has taken step into the field while has considered post-modern architecture and attention to the traditions of each race and nation. Modern architecture has a kind of Unitarianism based on the lack of attention to history and with globalization in it; but we observe pluralistic according to tradition and contextualism in style postmodern. Jencks says that "postmodernism is a selective combination of each tradition with prior style, and also continues the modernism and going beyond it "(Jencks, 1997).

In modern architecture is seen a kind of contentious relationship with nature and the bodies that have organic shapes that is on the contrary in the post-modern architecture, means there is an attention to the nature and inspiring by it. Modern architecture enters itself in a new realm by rejecting earlier anthropomorphic and poetic styles in favor of non-figurative and abstract geometries, but we see in the post-modern architecture that paying attention to the human aspects is an important part. There are many uses of abstract and meaningless forms in modern architecture while paying attention to the meaning and various forms in order to appeal is the aim in the postmodern architecture. We see a gap between thought and feeling due to lack of space and functionalism in modern architecture that post-modern architecture in this respect is opposite point of the modern architecture. Modern architecture in order to progress, and to achieve the aim destroyed the traditional and old neighborhoods of city to create a new urban signs that this matter was associated with strong protest and support of these tissues in post-modern architecture. Decoration and paying attention to the different interests and tastes have importance in post-modern while with the simplicity and low slogan has justified it in modern architecture. We see following the kind of unusual metaphysim in postmodern architecture that is not important in modern architecture. Functionalism and mathematical thinking govern in modern architecture According to the Jenks doctrine rule of modernism in architecture can be called improving the pragmatic that belief of that work was more with fewer features (Jencks, 1997).

But cultural thinking is dominant in addition to functionalism in postmodern architecture so it can be seen in the post-modern architecture a kind of pluralism, so the spirit of building of post-modern is compatible with democracy and the spirit of modern building with tyranny. Finally, post-modern architecture has had artistic vision than performance, which had been considered just doing in modern architecture (Robert, 2009).

\section{CONCLUSION}

In this study, we mentioned modern and post-modern art, as well as features, differences and similarities of modern and postmodern architecture. It can be analyzed with a special look that these styles pass a period of history of architecture that had been effective the socio-economic and environmental conditions and in particular philosophical conditions.

Perhaps, it can be said, modern architecture during the history that has had, was involved with a big problem with the name of war and inevitably has fixed it. For this reason, it could not be coordinated with comments and philosophical schools of modernity space but the post-modern architecture has formed with a sense of lack of shortages of this style, and yet freely and with rich intellectual backing. Modern architecture is a kind of security creator, the person of modern period is not looking for beauty and decoration, is looking for a place where runs away of homelessness and insecurity. Modern architecture began with the Civil period that attention to the industry had been principle and to succeed in the industry should be sacrificed anything, Ranging from human to human life and conditions. Post-modern era has been formed In contrast with giving value to human and his/her emotions not like modern period that ignores everything with calculator and jobber wisdom on the way to achieve the target. Post-modern architecture because of different feelings that have appeared in different places has breadth and diversity. Lyotar argues that undoubtedly post-modern is a part of the 
modern and in a sense precedes the modern. One effect only if it is first postmodern can be modern (Dibaj, 1998).

\section{REFERENCES}

1. Jencks, Charles (1997) What is postmodernism, translation Farhad Morteza'i, Tehran: Publication Marandiz.

2. Jawdat, MR (2005), "You architecture draws you, but I will make it" Proceedings of architecture and urbanism, Tehran: the treasure.

3. Dibaj, Seyyed Musa and Soltanzadeh, H. (1998), philosophy and architecture, Tehran: Cultural Research Bureau.

4. Raygani, N. (2014) a modern puzzle. Tehran: the lives and the world.

5. Alizadeh, Bakhtiar (2012), Bane architecture / post-modern architecture. Role of the world.

6. Qobadian, V. (2003), principles and concepts in contemporary architecture in the West, Tehran: Cultural Research Bureau.

7. Malpas, Simon (2007), postmodern, translated by Hussein patience, Tabriz University Press.

8. Nesbiyat, Keith (2010), theories of postmodernism in architecture, translated by Mohammad Reza Shiraz, Tehran: Straw.

9. Noruz Borazjani, Vida (2003), excerpts of architecture: the meaning and place, Tehran: the lives and the world.

10. Nozari, Ali 2000, postmodernity and postmodernism, publisher of the world.

11. Jabre Moghaddam, M. Hadi 2005, the city and modernity, Tehran, published by the Academy of Arts

12. Velibeyoglu. Koray 1999.Urban Design in the Postmodern Context. Izmir Institute of Technology. 13. Robert A.schneider 1998. The Postmodern City from an Early Modern Perspective. Weston Joan 2002 spring.Postmodern City. Sociology 266

14. Steven Best, Douglas Kellner (1997) The Postmodern Turn, Guilford Press.

15. http://www.oberlin.edu/sociology/syllabi\%202001-2002

16. http://forum.p30world.com/showthrea

17. www.PINKnet.Blogfa.com

18. http://mehrazi2013.blogfa.com/category/6 